\title{
Airports in the United States: Are They Really Breastfeeding Friendly?
}

\author{
Michael Haight ${ }^{1}$ and Joan Ortiz ${ }^{2}$
}

\section{Abstract}

Introduction: State and federal laws have been enacted to protect the mother's right to breastfeed and provide breastmilk to her infant. The Patient Protection and Affordable Care Act requires employers to provide hourly waged nursing mothers a private place other than a bathroom, shielded from view, free from intrusion. Minimum requirement for a lactation room would be providing a private space other than a bathroom. Workplace lactation accommodation laws are in place in 24 states, Puerto Rico, and the District of Columbia. These requirements benefit the breast-pumping mother in an office, but what about the breast-pumping mother who travels? Of women with a child under a year, 55.8\% are in the workforce. A significant barrier for working mothers to maintain breastfeeding is traveling, and they will need support from the workplace and the community. This study aimed to determine which airports offer the minimum requirements for a breast-pumping mother: private space other than a bathroom, with chair, table, and electrical outlet.

Study Design: A phone survey was done with the customer service representative at 100 U.S. airports. Confirmatory follow-up was done via e-mail.

Results: Of the respondents, 37\% $(n=37)$ reported having designated lactation rooms, $25 \%(n=25)$ considered the unisex/family restroom a lactation room, $8 \%(n=8)$ offer a space other than a bathroom with an electrical outlet, table, and chair, and $62 \%(n=62)$ answered yes to being breastfeeding friendly.

Conclusions: Only $8 \%$ of the airports surveyed provided the minimum requirements for a lactation room. However $62 \%$ stated they were breastfeeding friendly. Airports need to be educated as to the minimum requirements for a lactation room.

\section{Introduction}

$\mathbf{T}$ he Agency for Healthcare Research and Quality evidence report on Breastfeeding and Maternal and Infant Health Outcomes in Developed Countries demonstrated the numerous, positive health benefits that breastfeeding offers to both infant and mother. ${ }^{1}$ As a result, the American Academy of Pediatrics' policy statement, Breastfeeding and the Use of Human Milk, recommends exclusive breastmilk for the first 6 months of life followed by continued breastfeeding as complementary foods are introduced, with continuation of breastfeeding for 1 year or longer as mutually desired by mother and infant. ${ }^{2}$ Breastfeeding initiation rates are $76.5 \%$, yet only $16 \%$ are exclusively breastfeeding for the recommended duration of 6 months. ${ }^{3}$

The objective of the U.S. Department of Health and Human Services' Healthy People 2020 initiative is to increase the proportion of infants who have ever received breastmilk to $81.9 \%$, to $60.9 \%$ for those infants who are receiving some breastmilk at 6 months, and to $34.1 \%$ for infants who are still receiving some breastmilk at 1 year. The Healthy People 2020 goals are to have $46.2 \%$ of infants exclusively breastfeed through 3 months and $25.5 \%$ for infants at 6 months. ${ }^{4}$

The average maternity leave in the United States is 10 weeks ${ }^{5}$; therefore, mothers who work outside of the home are presented with the biggest obstacles when it comes to meeting these goals.

One might ask, with these strong recommendations and goals, does the infant have the right to receive exclusive breastmilk for the first 6 months of life? Kent ${ }^{6}$ debated the issue of the infants' right to receive breastmilk, stating the infant has little power in asserting his or her right. Kent concluded in his debate "that children should be viewed as having the right to be breastfed, not in the sense that mother is obligated to breastfeed the child, but in the sense that no one may interfere with the mother's right to breastfeed the child. Breastfeeding should be viewed as the right of the mother and child together." 6

\footnotetext{
${ }^{1}$ San Francisco-Fresno Program, University of California, San Francisco, Fresno, California.

${ }^{2}$ Limerick Inc., Burbank, California.
} 
The World Health Organization published a book in 2003 titled Global Strategy for Infant and Young Child Feeding ${ }^{7}$ that included the recommendation that infants should be exclusively breastfed for the first 6 months of life to achieve optimal growth, development, and health. One strategy that is recommended by the World Health Organization is to enact "imaginative legislation protecting the breastfeeding rights of the working women and establishing means for its enforcement."7 Not only is it the mother's right to give her baby milk, but it is the right of the baby to receive the best nutrition possible.

The United States has been successful in establishing laws at both the federal and state levels. At the federal level The Patient Protection and Affordable Care Act (H.R. 3590) section 4207 of the law amends the Fair Labor Standards Act, requiring an employer to provide hourly waged nursing mothers reasonable break time and a private place to express milk other than a bathroom, shielded from view, free from intrusion from coworkers and the public. ${ }^{8}$ Workplace Lactation Accommodation Laws are in place in 24 states along with Puerto Rico and the District of Columbia requiring companies to offer lactation accommodation for all women in the workplace. Breastfeeding women are protected under Title VII of the Civil Rights Act of 1964 (as amended by the Pregnancy Discrimination Act of 1978) according to a recent ruling on May 31, 2013 by the United States Court of Appeals for the Fifth Circuit. ${ }^{9}$ The minimum requirement for a lactation room would include a private space, other than a bathroom, with an electrical outlet, table, and chair.

The new federal and state laws benefit the breast-pumping mother in an office setting. What about the breast-pumping mother who travels for her job? Businesses have asked the U.S. Department of Labor, Wage and Hour Division whose responsibility is it if the employee travels to an off-site location. The Division's response was published in the Federal Register on December 21, 2010, stating it is the obligation of the employer to provide space, regardless of where the employee is located. ${ }^{10}$ The U.S. Department of Labor suggested the employer reach out to the client to allow the employee to use a space at the client's site for the purpose of expressing milk. This is a challenging request for both the employer and employee, as the employee may not be going to just one client's worksite. What about the reporter who is on the road, or when a business trip is required of the breast-pumping mother? Who does the employer reach out to in this situation to help locate a lactation room?

The U.S. Bureau of Labor Statistics reports $55.8 \%$ of women with a child under 1 year of age are in the work force. ${ }^{11}$ One of the major barriers for working mothers to sustain breastfeeding is traveling. Workplace lactation programs (WLPs) are now common in many national Fortune 500 companies and municipalities. Many mothers in a WLP often travel for work and needed advice regarding lactation facilities at various airports. Finding a clean, private room other than a bathroom to express her milk at the airport was the biggest challenge for the traveling breast-pumping mother. Therefore, we conducted a survey of the top 100 passenger-volume U.S. airports to assess their provision of a breastfeeding-supportive facility.

The objective of this study was to determine which airports offer the minimum requirements for a breast-pumping mother: private space, other than a bathroom, with a chair, table, and electrical outlet.

\section{Study Design}

A phone survey was conducted with the customer service representative at the top 100 passenger-volume U.S. airports. The annual passenger usage ranged from 43 million to 729 thousand. Questions were asked as to whether the airport was breastfeeding friendly and what accommodations it offered the traveling breast-pumping mother.

The answers received from the customer service representatives were e-mailed to the Public Relationship Department or placed in the comment section on the airport's Web site. We asked for confirmation of answers and provided 14 days to respond. If no response was given, then the customer service reply was used for evaluation. If further clarification was needed to confirm the airport met the minimum requirements for a lactation room, the airport's Web site was used.

This study was submitted for approval to the Children's Hospital Central California Institutional Review Board. It was determined this is not Human Subjects Research based on the study design not involving human subjects per $45 \mathrm{CFR}$ 46.102 (f).

\section{Results}

Eight of the 100 airports interviewed offered a private space other than a bathroom with an electrical outlet, table, and chair. It is important to note that $37 \%(n=37)$ reported having designated lactation rooms and that $25 \% \quad(n=25)$ considered the unisex/family/female restroom as a lactation room. Two percent $(n=2)$ of the airports offered no comment as to what was available in the lactation room. Two percent $(n=2)$ provided a private room for mothers to nurse their baby; it did not meet the minimum requirements for a breastpumping room, as it lacked an electrical outlet and a table. Eight percent $(n=8)$ offered a private space other than a bathroom with an electrical outlet, table, and chair. The eight airports that met minimum requirement for a breast-pumping mother are as follows: San Francisco International, California; Minneapolis-St. Paul International, Minnesota; Baltimore/ Washington International, Maryland; San Jose International, California; Indianapolis International, Indianapolis; AkronCanton Regional, Ohio; Dane County Regional, Wisconsin; and Pensacola Gulf Coast Regional, Florida.

Two percent $(n=2)$ of these eight lactation rooms were outside of the secured area.

Lactation rooms could be located on the airport's Web site and or/by signage in $7 \%(n=7)$ of the eight airports that stated they had lactation rooms.

E-mail confirmation was received by $43 \%(n=43)$ of the airports surveyed, and corrections were made if needed. More than half the airports $(62 \%, n=62)$ answered yes to being breastfeeding friendly. Below is a sampling of the quotes received from the e-mail responders:

Through the use of one of the family restrooms we can provide a safe, clean and private environment for lactating mothers. (Spokane Airport)

I think lactation rooms are as important as free Wi-Fi. (Pensacola, FL)

We do not have a dedicated room for a lactation facility. However, a family rest room located pre-security is designed for one person and can be locked from the inside. While this is 
less than ideal, we continue to seek alternatives. (LaGuardia Airport)

Yes we have lactation rooms - each restroom location in the airport has a private, lockable stall called a Family Restroom. The Family Restroom is a stall that includes a toilet, sink, mirror, baby changing station, electric outlets and seat. (Sea-Tac Airport)

Sky Harbor International Airport is a breast-feeding friendly airport that provides private, family restrooms in each of the airport's three terminals. Mothers may choose to nurse their infants or use a lactation pump in these private locations. (Phoenix)

The Airport terminal is a public building where nursing mothers are welcome to feed their baby on demand. But for those who may wish to have a little more privacy, we offer private, family restrooms throughout the terminal. They offer running water, a chair, an electrical outlet for pumping and a small table. As an employer, Reno-Tahoe Airport Authority supports breastfeeding. Mothers who wish to express breast milk during their workday while separated from their infant are provided a private room and appropriate breaks. (RenoTahoe International Airport)

A complete listing of the 100 airports surveyed with the findings can be found at www.limerickinc.com/pdf/US_ Airport_Lactation_Rooms.pdf

\section{Discussion}

Results show only eight out of 100 airports surveyed in the United States provide a private lactation room that meets the minimum requirements of a lactation room. The fact that only six of the eight offer a room inside the secure area, 37\% reported having designated lactation rooms, and $25 \%$ of those airports think a restroom is an appropriate place for a mother to either breastfeed her infant or express milk demonstrate the lack of understanding of the needs of the breast-pumping mother. In addition, only having six airports with a lactation room in the secure area makes it difficult for a mother to express her milk. A mother traveling will need to express her milk as close as possible to her boarding time to prevent engorgement and potential for mastitis.

A letter was sent to the Airport Council International (ACI) informing them of our findings, and we have yet to hear back from them. Each year the ACI does a Passenger Services Survey of the airports. ${ }^{12}$ Some questions that were asked by the ACI regarding services included questions on nail salons and massage and spa services, along with children's play areas. It is interesting that the ACI did not ask questions regarding lactation rooms; however, two airports did include it on the comment section. The breastfeeding mother who is traveling with her baby has different needs than the breastpumping mother who travels without her infant. The breastpumping mother has an increased need for a private, clean, space to express her milk. It is noteworthy that only two out of the 100 airports surveyed did provide a private room with a comfortable chair; however, there was no table and electrical outlet to plug in a breast pump. Traveling breast-pumping mothers' requirements can be met by society if there were clean, safe rooms other than a bathroom in airports and throughout the community in public buildings. This would move in the direction of normalizing breastfeeding.

The objective of the U.S. Department of Health and Human Services' Healthy People 2020 initiative is to increase the proportion of infants who have ever received breastmilk to $81.9 \%$, to $60.9 \%$ for those infants who are receiving some breastmilk at 6 months, and to $34.1 \%$ for infants who are still receiving some breastmilk at 1 year. ${ }^{4}$ The Healthy People 2020 goals are to have $46.2 \%$ of infants exclusively breastfeed through 3 months and $25.5 \%$ for infants at 6 months. ${ }^{4}$ These are reachable goals if society accepts breastfeeding as the norm. Accepting breastfeeding as the norm means removing the obstacles for breastfeeding mothers in all settings while at work or traveling. Breastfeeding initiation rates have increased to $76.5 \%$, but only $16 \%$ are exclusively breastfeeding for 6 months in the United States. ${ }^{3}$

To increase the duration that a mother breastfeeds, mothers need to be supported. It is important to note that $62 \%$ of the airports considered themselves "breastfeeding friendly," meaning breastfeeding in public was acceptable. Yet, only $37 \%$ reported having designated lactation rooms, and $25 \%$ considered the bathroom as an acceptable lactation room. Support includes professional resources that a breastfeeding mother can reach out to when she has questions about working or traveling away from her baby. Support also includes the provision of an appropriate space for the breastfeeding mothers to express their milk. The Federal Government realizes that expressing food for your baby in a bathroom is not appropriate, hence the federal law. The Patient Protection and Affordable Care Act requires employers to provide hourly waged nursing mothers a private place to express their milk other than a bathroom, shielded from view, free from intrusion from co-workers and the public. ${ }^{8}$ The Academy of Breastfeeding Medicine's position regarding breastfeeding states "breastfeeding is both a woman's and a child's right, it is therefore the responsibility of the healthcare system, the media, business and marketing sectors, government, and society in general to support and enable each women to fulfill her breastfeeding goals and to eliminate obstacles and constraints to initiating and sustaining optimal breastfeeding practices."13

In order to reach the Healthy People 2020 goals of $60.6 \%$ of babies receiving breastmilk at 6 months, ${ }^{4}$ support and regulations will need to be established to help support the working, traveling breast-pumping mother. Breastfeeding women are protected under Title VII of the Civil Rights Act of 1964 (as amended by the Pregnancy Discrimination Act of 1978) according to a recent ruling on May 31, 2013 by the United States Court of Appeals for the Fifth Circuit. The Fifth Circuit noted the biological fact that lactation is a physiological condition distinct to women who have undergone a pregnancy. ${ }^{9}$ Accordingly, under Title VII of the Civil Rights Act of 1964 and the Pregnancy Discrimination Act, firing a woman because she is lactating or expressing milk is unlawful sex discrimination because men as a matter of biology could not be fired for such a reason. ${ }^{9}$

In December 2012, the Equal Employment Opportunity Commission (EEOC) identified accommodating pregnancyrelated limitations under the Americans with Disabilities Act Amendments Act (ADAAA) and the Pregnancy Discrimination Act as a national enforcement priority through $2016 .{ }^{14}$ The goal for the EEOC is to establish clear and strong guidance to employers on their legal obligation to accommodate pregnant workers. The EEOC states that employers must provide a private place, other than a bathroom, for mothers to express their milk in the workplace. Both the Pregnancy Disability Act and ADAAA require employers to accommodate employees 
with limitations arising out of pregnancy just as they would treat those with a similar limitation arising out of disability. A woman's right to breastfeed/breast pump has been ruled a Civil Right. Lactation is ruled as pregnancy related and is covered under the ADAAA.

The timing is right to require lactation rooms become a part of Americans with Disabilities Act Standards for Accessible Design. When lactation rooms become the standard for buildings, it will alleviate the stress of employers having to accommodate the breast-pumping mother who works offsite. It will also allow the working mother to continue in her current position without having to make special accommodations for her in the workplace. Lactation rooms becoming the norm in buildings would remove a major obstacle preventing working breast-pumping mothers from reaching their breastfeeding goals and will be a move in the direction of establishing breastfeeding as the cultural norm.

Initiation rates are increasing; however, lack of support and societal barriers hinder breastfeeding mothers from reaching their breastfeeding goals. WLPs that provide a supportive environment for mothers to express their milk in a private room, along with the ongoing support from a lactation consultant, have been proven to be effective in exceeding the Healthy People 2010 goal of having $50 \%$ continuing to provide breastmilk for at least 6 months. Ortiz et al. ${ }^{15}$ reported $58 \%$ $(n=462)$ of working breastfeeding mothers who participated in a WLP were providing breastmilk at 6 months. This stresses the importance of the support of a lactation consultant and a supportive work environment. The Healthy People 2020 objective is to increase the proportion of employers that have worksite lactation support programs from $25 \%$ to $38.0 \%{ }^{4}$ Although the Patient Protection and Affordable Care Act requires employers to provide an hourly waged nursing mother time and a private place to express her milk and state laws require that all breastfeeding mothers have lactation accommodations in the workplace, the challenge is still present for the breast-pumping mother who travels. With more than $50 \%$ of women in the workforce having a child under the age of a year, supporting the breastfeeding mother has the potential to impact such critical issues of health benefits to both the mother and baby in addition to having a positive economic benefit. A detailed pediatric cost analysis based on the Agency for Healthcare Research and Quality of the U.S. Department of Health and Human Services report concluded that if $90 \%$ of the U.S. mothers would comply with the recommendation to breastfeed exclusively for 6 months, there would be a savings of $\$ 13$ billion per year. ${ }^{16}$

\section{The Future: Next Steps}

To reach the objective of the U.S. Department of Health and Human Services' Healthy People 2020 initiative, we need society to support the working breast-pumping mother who works outside of the office. Lactation rooms need to become a part of the Americans with Disabilities Act Standards for Accessible Design. Some states are now introducing legislative changes in the building code. Lactation rooms becoming the norm in buildings will remove one of the barriers faced by the traveling working breast-pumping mothers. Further research needs to be completed to prove that a supportive community can only have a positive effect on increasing breastfeeding rates. This change would be a move in the direction of making breastfeeding of and providing breastmilk to an infant the cultural norm.

\section{Conclusions}

Only $8 \%$ of the airports surveyed provided the minimum requirements for a lactation room. However, $62 \%$ stated they were breastfeeding friendly. Airports need to be educated to the minimum requirements for a lactation room.

\section{Disclosure Statement}

J.O. is co-owner of Limerick Inc. M.H. declares no competing financial interests.

M.H. participated in designing the study, carried out the final analyses, reviewed and revised the manuscript, and submitted the final manuscript. J.O. conceptualized and designed the study, conducted data collection, and drafted the initial manuscript. Both authors approved the final manuscript as submitted and agree to be accountable for all aspects of the work.

\section{References}

1. Agency for Healthcare Research and Quality. Breastfeeding and Maternal and Infant Health Outcomes in Developed Countries, EvidenceReport/Technology Assessment Number 153. April 2007. AHRQ Publication Number 07-E007. Available at http://archive.ahrq.gov/downloads/pub/evidence/ pdf/brfout/brfout.pdf (accessed September 23, 2014).

2. Section on Breastfeeding. Breastfeeding and the use of human milk. Pediatrics 2012;129:e827-e841.

3. Division of Nutrition, Physical Activity, and Obesity, Center for Chronic Disease Prevention and Health Promotion. Breastfeeding Report Card: United States/2013. Available at www.cdc.gov/breastfeeding/pdf/2013Breast feedingReportCard.pdf (accessed September 18, 2014).

4. U.S. Department of Health and Human Services. Maternal, Infant, and Child Health. Healthy People 2020. 2010. Available at www.healthypeople.gov/2020/TopicsObjectives 2020/objectiveslist.aspx?topicId $=26$ (accessed September 22, 2014).

5. Maternal and Child Health Bureau, Health Resources and Services Administration, U.S. Department of Health and Human Services. Women's Health USA 2011. 2011. Available at www.mchb.hrsa.gov/whusa11/hstat/hsrmh/ pages/233ml.html (accessed September 18, 2014).

6. Kent G. Debate Child feeding and human rights. Int Breastfeed J 2006;1:27.

7. World Health Organization. Global Strategy for Infant and Young Child Feeding. World Health Organization, Geneva, 2003, p. 14.

8. U.S. Department of Labor. Section 7(r) of the Fair Labor Standards Act-Break Time for Nursing Mothers Provision. 2011. Available at www.dol.gov/whd/nursingmothers/ Sec7rFLSA_btnm.htm (accessed September 22, 2014).

9. U.S. Equal Employment Opportunity Commission Fifth Circuit Holds Lactation Discrimination Is Unlawful Sex Discrimination [press release]. May 31, 2013. Available at www.eeoc.gov/eeoc/newsroom/release/5-13-13a.cfm (accessed September 22, 2014).

10. Federal Register, Vol. 75, No. 244, 80073-80079. Tuesday, December 21, 2010. Available at www.webapps.dol.gov/ federalregister/PdfDisplay.aspx ?DocId $=24540$ (accessed September 22, 2014). 
11. U.S. Bureau of Labor Statistics. Current Population Survey, Employment Characteristics of Families. Table 6: Employment Status of Mothers with Own Children under 3 Years Old by Single Year of Age of Youngest Child and Marital Status, 2010-2011 Annual Averages. 2012. Available at www.bls.gov/news.release/famee.t06.htm (accessed September 22, 2014).

12. Airport Council International. Airport Passenger Survey as November 2012. Available at www.aci-na.org/content/ 2012-passenger-services-survey (accessed September 22, 2014).

13. Marinelli K, Moren K, Taylor J, et al. Breastfeeding support for mothers in workplace employment or educational settings: Summary statement. Breastfeed Med 2013;8: 137-142.

14. U.S. Equal Employment Opportunity Commission. Strategic Enforcement Plan for FY2013-2016 B3. 2012. Available at www.eeoc.gov/eeoc/plan/sep.cfm (accessed September 22, 2014).

15. Ortiz J, McGilligan K, Kelly P. Duration of breast milk expression among working mothers enrolled in an employer-sponsored lactation program. Pediatr Nurs 2004; 30:111-119.

16. Bartick M, Reinhold A. The burden of suboptimal breastfeeding in the United States: A pediatric cost analysis. $\mathrm{Pe}$ diatrics 2010;125:e1048.

Address correspondence to: Joan Ortiz, RN

Limerick Inc.

2150 North Glenoaks Boulevard Burbank, CA 91504-4327

E-mail: joan.ortiz@limerickinc.com 